\title{
Assessing Double Acid-Etched Implants Submitted to Orthodontic Forces and Used as Prosthetic Anchorages in Partially Edentulous Patients
}

\author{
Rugani de Cravero Marta ${ }^{1}$ and Ibañez Juan Carlos ${ }^{2, *}$
}

${ }^{1}$ Doctor in Dentistry and Assistant Professor of Orthodontics, School of Dentistry, Universidad Nacional de Córdoba,
República Argentina and ${ }^{2}$ Doctor in Dentistry, Private Practice, Obispo Oro 414 Córdoba (5000) República Argentina

Abstract: The use of implants as anchorage for orthodontic forces seems to be a good alternative in partially edentulous patients needing orthodontic treatment.

This study is aimed at assessing the performance and behavior of microtextured surface endosseous implants obtained by means of a double acid etching against orthodontic forces, as well as their adequacy to be used first as anchorage and later as fixtures for the definitive prosthesis.

Materials and Methods: A total of 93 double acid-etched surface parallel wall implants (Osseotite® Implants, Implant Innovations Inc., Palm Beach, Florida, USA) were inserted in 38 partially edentulous patients prior to orthodontic treatment This was carried out by following two-stage surgery protocols in the maxilla as well as in the mandible.

After a healing period of six months for the maxilla and four months for the mandible, the implants were used as anchorage for sliding, compression and traction orthodontic forces between 100 to $200 \mathrm{~g}$ by means of Ni-TI springs.

Bone level and Resonance Frequency Analysis (RFA) were measured before and after the introduction of the orthodontics forces.

Results: After removal of the orthodontics appliances, all the implants remained stabile and served as support for prosthetic replacement of missing teeth. The bone level showed no variation even when a positive difference $0.02 \pm 0.38 \mathrm{~mm}$ was noticed. The RFA scored a significant difference $(\mathrm{p} \leq 0.03)$ between the initial Implant Stability Quotient (ISQ) values (66) and the final ones (68).

Conclusions: These findings showed that Osseotite implants were able to support the orthodontic forces applied during this investigation, maintaining osseointegration without significant variation in bone level. Therefore, they can be used to support dental prosthesis once they have been used as orthodontic anchorage under the cited conditions.

Key Words: Osseointegrated implants, orthodontic forces, absolute anchorage.

\section{INTRODUCTION}

For many years osseointegrated implant have been used to replace missing teeth with excellent results [1-2-3]. Other indications have been proposed for the use of implants, like maxillofacial or orthodontic anchorage [4-5-6-7]. The use of implants as anchorage for orthodontic forces seems to be a good alternative in partially edentulous patients that need orthodontic treatment. [8-9-10-11-12]

The advantage of using an osseointegrated implant as orthodontic anchorage is that the implant is absolutely immobile because of the absence of periodontal ligament. Thus the applied forces acts on the bone without occurrence of bone resorption. This phenomenon is called "absolute anchorage" [13].

Higuchi and Slack [14] showed good results by using machined surface implants in humans. Similar results were achieved by Thilander [15], Odman [16] and Roberts [17].

In some of these studies, implants were placed in areas of the mandible or the maxilla where teeth were absent, like the palate, the retromolar area or others.

*Address correspondence to this author at the Obispo Oro 414, Cordoba, Argentina; Tel/Fax: 54-351-4680156; E-mail: dribanez@ibaimplantes.com
In some cases the best option might consist in placing the implant or implants into the site where the missing tooth or teeth should be replaced. In doing so, the fixture will function as orthodontic anchorage first and then as prosthetic anchorage. Several authors have presented this concept and showed how to plan implant position by working with different types of implants. [18-19-20]

The present study was aimed at assessing the performance and behavior of endosseous implants with a microtextured surface obtained by means of a double acid etching against orthodontic forces as well as their adequacy to be used first as anchorage and subsequently, as fixtures for the definitive prosthesis.

\section{MATERIAL AND METHODS}

This prospective study was performed in 38 patients, 9 men and 29 women between 22 and 64 years of age and partially edentulous requiring orthodontic treatment. The exclusion criteria for the selection of the cases were: systemic condition that impeded oral surgery, drugs, alcohol or excessive use of cigarettes (no more than 12 cigarettes per day), pregnancy as well as growing patients.

These patients requested orthodontic treatment for aesthetic or functional motives and gave informed consent to 
take part in the investigation. The treatment was performed in private practice as well as at the School of Dentistry of the Cordoba National University between March 2002 and March 2006. For the purpose of statistical analysis, the patients were divided into 3 groups: 22 to 42 years old $(n=16)$, 42 to 53 years old $(n=15)$ and 53 to 64 years old $(n=7)$. Most of the implants were placed in group 1.

Clinical, radiographic and cephalometric studies were carried out. Splints for mandibular reposition were used in all the cases and study models were mounted in semi adjustable articulator (SAM III, Great Lakes Orthodontics Ltd., NY, USA) by using facial bow and centric relation records. A second pair of casts was made in order to determine the final teeth setup and the sites where implants had to be replaced. The diagnostic cast of teeth to be replaced was made available to the surgeon along with a surgical guide. (Fig. 1).

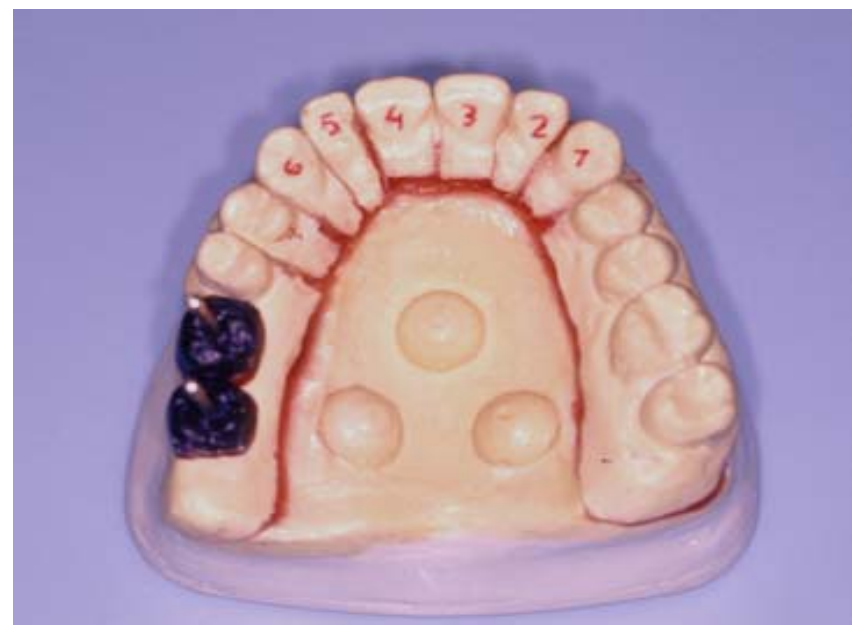

Fig. (1). A diagnostic teeth setup was prepared and a wax-up was done in order to write the surgical guide.

A total of 93 double acid etched surface implants (Osseotite ${ }^{\circledR}$ Implant Innovations Inc., Palm Beach, Florida, USA) were inserted into the sites prior to orthodontic treatment. 43 implants were placed in the mandible and 50 implants in the maxilla. The implants placed were unequally distributed into five groups of patients. A group of nine patients had only 1 (one) implant placed, a group of twelve patients had 2 (two) implants placed; ten patients had 3 (three) implant placed, 6 others had 4 (four) implants placed, and one patient had 6 (six) implants placed.

All implants were traditional straight wall implants with hybrid (machined surface at the first $3 \mathrm{~mm}$ from the occlusal area and double acid-etched surface from this point to the apical area) and were inserted into the sites according to the two stage surgery protocol. [21-22] Bone quality was determined during the drilling procedures [23] and no irrigation was used during implant insertion [22-24]

Distribution of implants according to their width and length, tooth and jaw position and patients' gender are shown in Tables 1, 2 and 3. Bone quality is shown in Table 4.

Table 1. Distribution of Implants According to their Width and Length

\begin{tabular}{|c|c|}
\hline Width and Length (mm.) & Number of Implants \\
\hline \hline $4 \times 10$ & 14 \\
\hline $4 \times 11.5$ & 19 \\
\hline $4 \times 13$ & 19 \\
\hline $5 \times 10$ & 16 \\
\hline $5 \times 11,5$ & 15 \\
\hline $6 \times 10$ & 5 \\
\hline $6 \times 11,5$ & 5 \\
\hline
\end{tabular}

Table 2. Distribution of Implants According to Gender

\begin{tabular}{|c|c|c|}
\hline Gender & Number of Patients & Number of Implants \\
\hline \hline Female & 29 & 77 \\
\hline Male & 9 & 16 \\
\hline
\end{tabular}

After a healing period of six months for the maxilla and four months for the mandible, a second stage surgery was performed and titanium healing abutments were placed.

At this point, the selection of the implants that would be loaded and used as anchorage for orthodontic forces was made in accordance with the following success criteria: lack of pain or discomfort, absence of clinical mobility, no infection or important inflammation, absence of peri-implant radiolucency, absence of progressive or severe bone loss (no more than $2.0 \mathrm{~mm}$ the first year and no more than $0.2 \mathrm{~mm}$ per year after the first one) and Implant Stability Quotient (ISQ) $=50$ or more.

In order to be selected for anchorage use, the implants had to meet all the selection criteria.

Table 3. Distribution of Implants According to Tooth Position and Jaw (FDI)

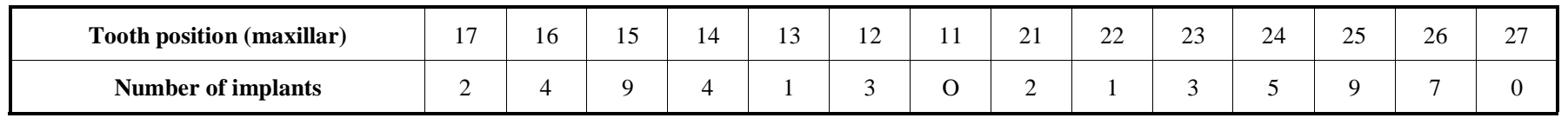

\begin{tabular}{|c|c|c|c|c|c|c|c|c|c|c|c|c|c|c|}
\hline Tooth position (mandible) & 47 & 46 & 45 & 44 & 43 & 42 & 41 & 31 & 32 & 33 & 34 & 35 & 36 & 37 \\
\hline
\end{tabular}


Table 4. Distribution of Implants According to Bone Type

\begin{tabular}{|c|c|}
\hline Bone Quality & Number of Implants \\
\hline \hline I & 2 \\
\hline II & 49 \\
\hline III & 35 \\
\hline IV & 7 \\
\hline
\end{tabular}

All installed implants showed osseointegration, thus meeting the selection criteria. All implants were, therefore, used for orthodontic anchorage.

Titanium straight posts (Gingi-Hue Post, Implant Innovations Inc., Palm Beach, Florida, USA) were placed and fixed with gold screws (Gold-tite Square Screw, Implant Innovations Inc., Palm Beach, Florida, USA) and torqued to 35 $\mathrm{Ncm}$ with the appropriate device. (Torque Indicator Kit, Biomet 3i, Palm Beach, Florida, USA). Resin temporary crowns were prepared and cemented on the posts with definitive cement. (Ketac- Cem 3M ESPE, St. Paul, USA).

“Synergy” RMO ${ }^{\circledR}$ (Rocky Mountain Orthodontics, Colorado, USA), or "Clarity" $3 \mathrm{M}^{\circledR}$ (3M Unitek, CA, USA) brackets were cemented on the temporaries. The same brackets were used in the remaining teeth when implementing orthodontic treatment.

The implants used as anchorage were submitted to sliding, compression and traction forces by means of Ni-Ti Sentalloy closed and open coil springs. Closed springs were placed from the hook of the implant's bracket to the hook of the adjacent tooth's bracket, while open springs were placed between both brackets along the wire. (Figs. $\mathbf{2}$ and $\mathbf{3}$ ).

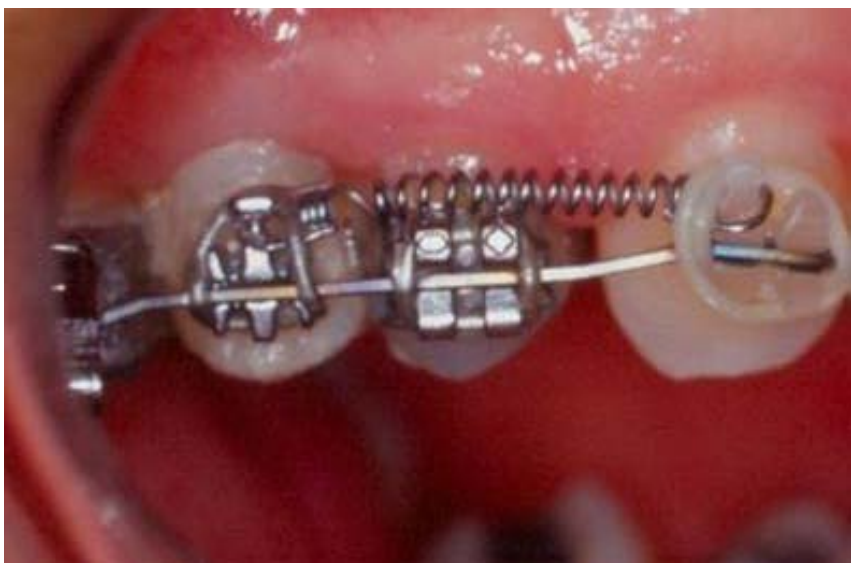

Fig. (2). Closed spring placed from the hook of the implant's bracket (site 15) to the hook of the tooth's bracket (tooth 13).

Closed springs were used in $51.6 \%$ of the implants $(\mathrm{n}=$ 48) while open springs were used in $48,4 \%$ of the cases $(n=$ 45).

The springs produced forces between 100 to $200 \mathrm{~g}$ depending on the spring selected for each case. When inactive, closed springs are $3 \mathrm{~mm}$ long but can reach $15 \mathrm{~mm}$ when they are activated, keeping a constant force throughout their length. Beside open springs are $15 \mathrm{~mm}$ long and can be compressed to $3 \mathrm{~mm}$, maintaining a constant force.

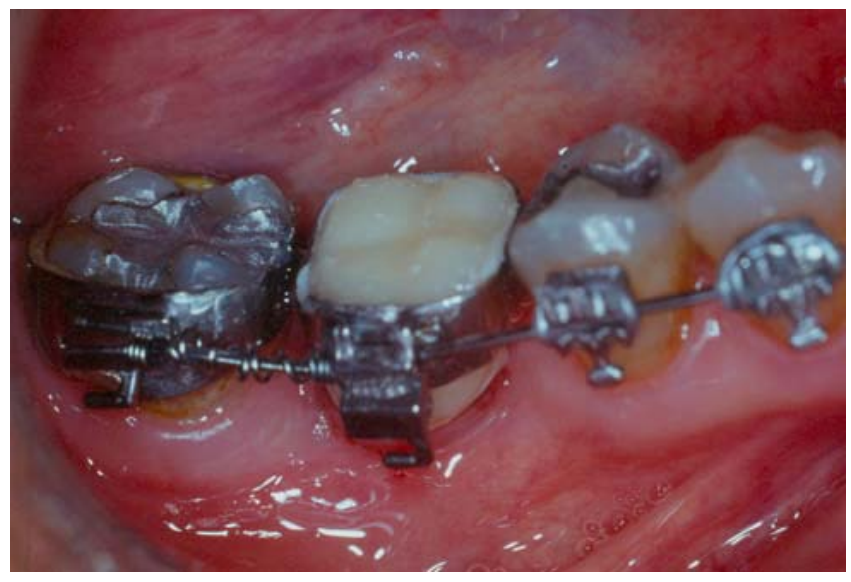

Fig. (3). Open springs placed between the hook of the implant's bracket (site 46) and the tooth's bracket (tooth 47).

Twenty one implants received $100 \mathrm{~g}$ springs, 33 implants received $150 \mathrm{~g}$ springs and 39 implants received $200 \mathrm{~g}$ springs. Tooth movements were between 0.6 to $7.5 \mathrm{~mm}$ (mean: $1,7 \mathrm{~mm}$ ) and implants were used as orthodontic anchorage for periods ranging from 2 to 9 months (mean: 3.5 months).

On the same day the implants were loaded and used as orthodontic anchorage, bone level and gingival index were measured, mobility was tested and RFA was performed.

Bone level was determined by taking standardized radiographs.[25-26] One UNI-BITE® (Dentsplay Rinn, Illinois, USA) x-ray holder was used in each case after individualize it with Duralay resin in order to be able to achieve the same position before and after orthodontic forces were applied (Fig. 4).

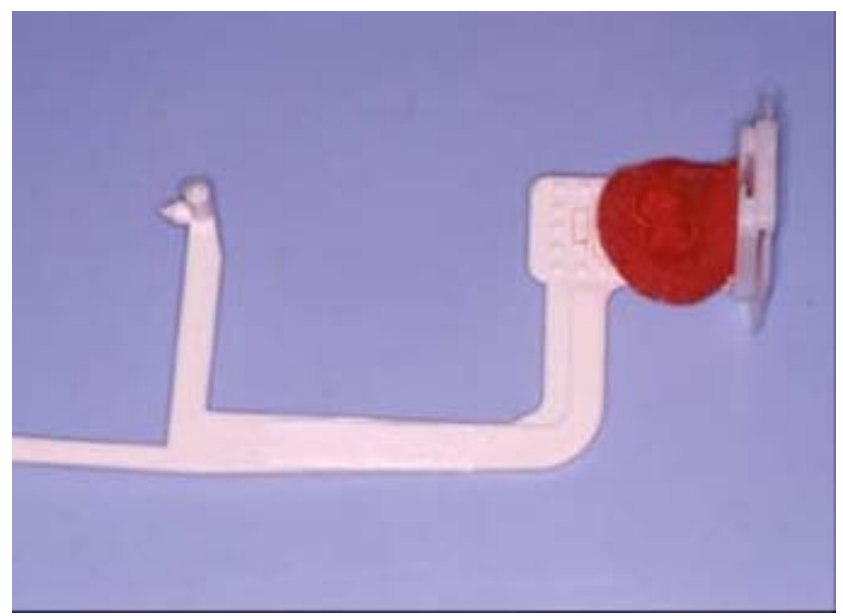

Fig. (4). Bone level was determined taken standardized radiographs. One UNI-BITE® $\mathrm{x}$-ray holder was used in each case after individualize it with Duralay resin in order to be able to achieve the same position before and after orthodontic forces were applied.

A Teflon ring specially made for this study, was attached to the X-ray apparatus with a groove on its inner face, where the positioner was placed. This was in order to be able to center the film and replicate the same position later on. 
The x-rays were developed in an automatic machine in order to standardize density and contrast. Then they were digitalized at 1200 dpi. Gray scale and pseudo-coloration images were analyzed by using Nemoceph Dental Studio ${ }^{\circledR}$ software 2005 version. (Software Nemotec S.L.,Visiodent SA.France). Mesial and distal measurements were taken from the implant-abutment connection to the first implantbone contact [27-28-29] by using a triple-blind method. These measurements were compared to the ones obtained with the same method at the moment when orthodontic forces were eliminated. (Fig. 5).

Soft tissue evaluation was performed according to Loe and Silness index [30]

Mobility was tested with a metallic instrument at implant level [31] before abutment placement and when the abutment was removed.

Resonance Frequency Analysis was performed by using an Osstell device (Integration Diagnostics AB, Göteborg, Sweden) and connecting a Type F1 sensor (Integration Diagnostics AB, Göteborg, Sweden) at implant level before abutment's placement.[32-33-34] The ISQ values obtained were compared with the ones obtained after orthodontics forces were removed.

When orthodontic treatment was finished all the implants were used for supporting single permanent prosthetic restorations.

\section{RESULTS}

After the removal of orthodontics forces all the implants remained firm, without movement, acting as "absolute anchorage" and serving as support for the prosthetic replacement of missing teeth. In the $100 \%$ of the cases, the implants were used as fixtures for the definitive crowns.

According to the success criteria for this study, $100 \%$ of the implants were successful.

The statistical analysis of the corresponding osseous level data was carried out in accordance with the Student T test for paired samples and the test of variance no-parametric of Kruscal Wallis and test $U$ of Man Whitney. The level of significance accepted was $\mathrm{p} \leq 0.05$.

No significant changes were found at bone level neither for mesial $(\mathrm{p} \leq 0.6)$ nor for distal $(\mathrm{p} \leq 0.3)$ bone level despite a positive difference $(0.02 \pm 0.34 \mathrm{~mm})$ in both sites bone level was found.

Statistic analysis of bone level in relation to gender, age and bone type are shown in Tables 5, 6 and $\mathbf{7}$.

The Resonance Frequency Analysis scored a significant difference $(p \leq 0.03)$ between the initial ISQ values (mean value: 66.26) and the final ones (mean value: 68.26) but without significant differences in relation to gender, age, distribution, bone type length and width of the implants.

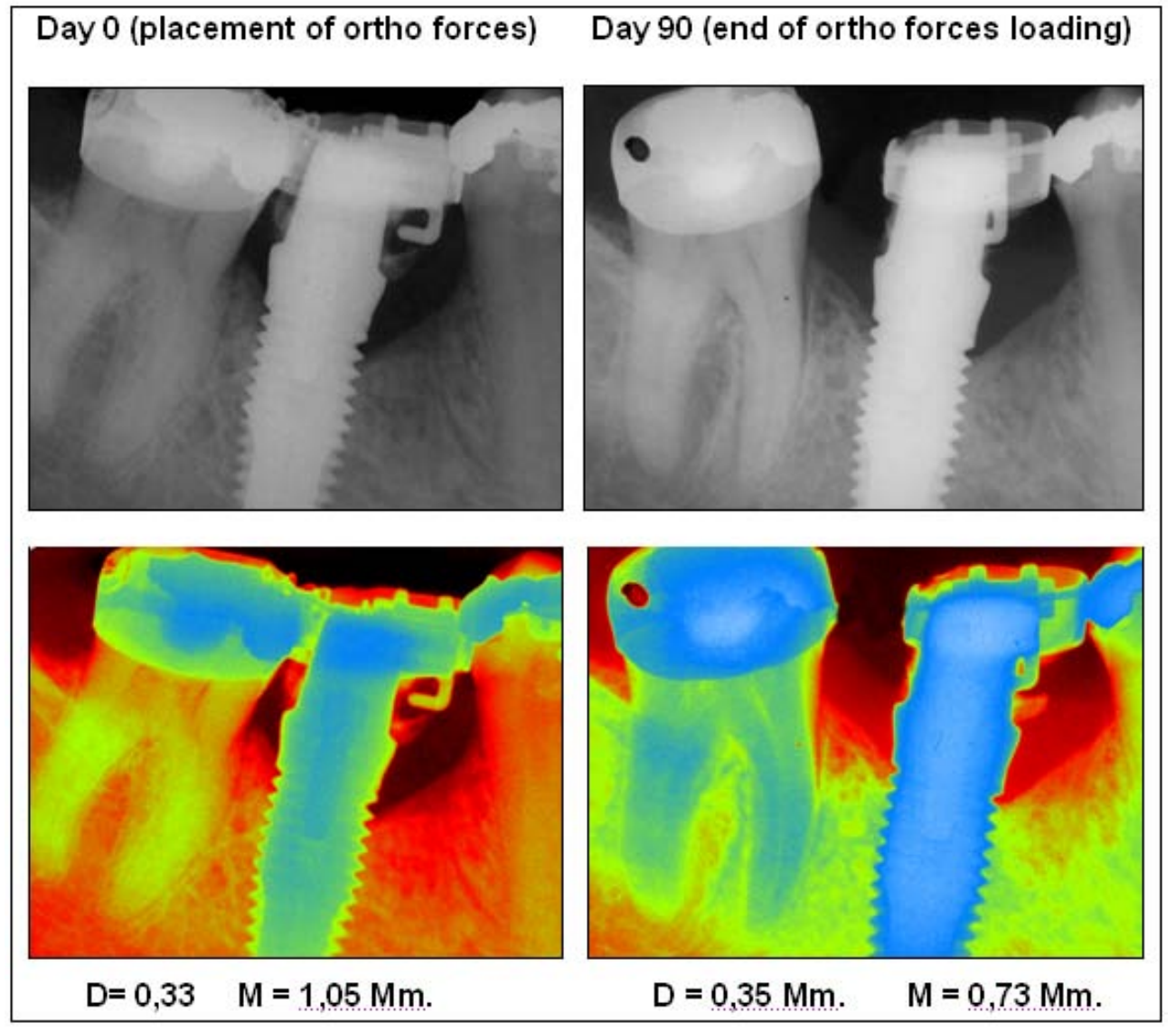

Fig. (5). Pre and post peri-apical x-rays of case 7. Normal view and pseudo coloration view were bone level can be observed. An Osseotite implant was used as orthodontic anchorage in site 46 . The movement of tooth number 47 was $3.6 \mathrm{~mm}$ and the forces were acting during 90 days. 
Table 5. Bone Level Remodeling in Relation to Gender

\begin{tabular}{|c|c|c|c|c|c|c|c|c|}
\hline \multirow{2}{*}{ Gender } & N & Mean & SD \pm & Minimum & Maximum & \multicolumn{3}{|c|}{ Bone remodeling (\%) } \\
\cline { 5 - 9 } & & & & & & Negative & Positive \\
\hline \hline Female & 77 & 0.00 & \pm 0.28 & 1.38 & -1.09 & $19(25 \%)$ & $57(74 \%)$ & $1(1 \%)$ \\
\hline Male & 16 & 0.06 & \pm 0.49 & 1.19 & -0.99 & $6(38 \%)$ & $9(56 \%)$ \\
\hline
\end{tabular}

n: Number of implants.

Table 6. Bone Level Remodeling in Relation to Age

\begin{tabular}{|c|c|c|c|c|c|c|c|c|}
\hline Groups According to Age & $\mathbf{N}$ & Mean & SD \pm & Minimum & Maximum & Negative & Positive & Null \\
\hline $\begin{array}{c}1 \\
(22-42)\end{array}$ & 38 & 0.02 & \pm 0.43 & 1.38 & -1.09 & $12(31 \%)$ & $25(66 \%)$ & $1(3 \%)$ \\
\hline $\begin{array}{c}2 \\
(42-53)\end{array}$ & 34 & -0.01 & \pm 0.21 & 0.43 & -0.60 & $10(29 \%)$ & $23(68 \%)$ & $1(3 \%)$ \\
\hline $\begin{array}{c}3 \\
(53-64)\end{array}$ & 21 & 0.01 & \pm 0.27 & 0.45 & -1.01 & $3(14 \%)$ & $18(86 \%)$ & - \\
\hline
\end{tabular}

n: Number of implants.

Table 7. Bone Level Remodeling in Relation to Bone Type

\begin{tabular}{|c|c|c|c|c|c|c|c|c|}
\hline \multirow{2}{*}{ Bone Quality } & N & Mean & SD \pm & Minimum & Maximum & \multicolumn{3}{|c|}{ Bone remodeling (\%) } \\
\cline { 4 - 9 } & & & & & & & Negative & Positive \\
\hline \hline I & 2 & -0.15 & 0.17 & -0.03 & -0.27 & $2(100 \%)$ & - \\
\hline II & 49 & -0.01 & 0.26 & 0.36 & -1.09 & $14(29 \%)$ & $34(69 \%)$ & $1(2 \%)$ \\
\hline III & 35 & 0.03 & 0.32 & 1.19 & -0.99 & $7(20 \%)$ & $27(77 \%)$ & $1(3 \%)$ \\
\hline IV & 7 & 0.11 & 0.69 & 1.38 & -1.00 & $2(29 \%)$ & $5(71 \%)$ & - \\
\hline
\end{tabular}

n: Number of implants.

Loe and Silness Gingival Index showed the absence of gingival inflammation in 26 implants (28\%), mild inflammation in 54 implants $(54 \%)$, and moderate inflammation in 13 implants (14\%). In 80 implants $(86 \%)$ the probing depth was less than $2 \mathrm{~mm}$ and in 13 implants (14\%) the depth was $3 \mathrm{~mm}$. No implants showed probing depth exceeding $3 \mathrm{~mm}$ 's.

A follow- up was performed 12 to 48 months after the definitive prostheses were inserted. The success rate obtained was $100 \%$ for all the implants placed.

\section{DISCUSSION}

The high success rate $(100 \%)$ achieved in the present study in both the maxilla as well as in the mandible might likely be related to the characteristics of the implant surface. The particular double acid-etched surface used in this study is a bio-engineered surface created by an acid-etching process by using hydrochloric and sulfuric acid applied to a commercially-pure titanium implant. This textured surface prevents the contraction of the fibrin clot, away form the implant surface rendering the surface osteoconductive. Since the fibrin clot is retained by the osteoconductive implant surface, the osteogenic cells generate bone tissue directly on the implant surface through a process called "contact osteogenesis" that results in an accelerated early bone healing [35]. Furthermore, when compared to the machined surface, DAE surface exhibited a statistically significantly higher percentage of bone-to-implant contact in poor quality bones [36], as well as a higher cumulative success rate in clinical studies [22-24-34-37-38-39-40].

Higuchi and Slack 1991 [4] reported similar success rates when using machined implants, but most of the implants used were placed in the mandible.

Odman et al. [17] used 23 machined titanium implants in nine partially edentulous adult patients as orthodontic an- 
chorage to perform different types of orthodontic tooth movements: tipping, torquing, rotation, intrusion, extrusion, and those associated with bodily movements. The total orthodontic treatment period varied between 4 and 33 months. All the osseointegrated titanium implants used as orthodontic anchorage remained in position after orthodontic loading and were used as abutments for permanent prosthetic constructions.

In 2002 Trisi and Rebaudi [41] used implants for orthodontic anchorage in forty-one adult patients. Implants were placed in different sites and all implants remained stable in the bone up to 12 months of loading, and all were osseointegrated.

Werhbein et al. [42] achieved similar results by using SLA surface implants placed in the mid-palatal and the retromolar area.

The characteristics of the forces used to perform tooth movements could have an influence too. Various authors [43-44-45] showed that Ni-Ti springs produced a very slight, continued and physiologic force that is very well accepted and tolerated by the bone.

Aldikacti et al. [46] placed SLA implants in the maxilla of $3 \mathrm{dogs}$ and in the mandible of $5 \mathrm{dogs}$, and super elastic nickel-titanium coil springs were activated between the SLA implants and the canines, producing a force of $200 \mathrm{~g}(2 \mathrm{~N})$. Two unloaded implants ( 1 in the maxilla, 1 in the mandible) were used for control purposes. Histological analysis shows that the corticalization of bone trabeculae is thicker in loaded than in unloaded implants. New bone formation at the level of the crest was slightly superior in the test implants. The mean bone-implant contact values of the test implants for the maxilla and mandible were $40.23 \%$ and $49.33 \%$, respectively. In the control implants, the bone-implant contact value was $67.91 \%$ for the maxilla and $49.23 \%$ for the mandible.

Saito et al. [47] placed two machine surface implants in healed mandibular extraction sites of the second and third premolars on each side, in 4 adult male beagle dogs. 18 weeks later, the implants were surgically uncovered, and second-stage abutments with soldered edgewise tubes were attached. One segment in each dog served as a loaded side, and the arch wire was calibrated to produce $200 \mathrm{~g}$ of lateral force on the fourth premolar. The contralateral segment served as an unloaded side and was not subjected to orthodontic force. Sectional wires were activated biweekly 24,28 and 32 weeks. The percentage of peri-implant bone volume was calculated and defined as an index of osseointegration. Not only was there no statistical difference in the percent of peri-implant bone volume between the loaded and unloaded sides, there was also no statistical difference between the compression and tension sides in both loaded and unloaded implants. This suggests that the implants maintained rigid osseointegration.

Trisi and Rebaudi [41] showed the histological results of seven implants that were removed at the end of the orthodontic therapy, after 2, 4, 6, and 12 months of orthodontic load. Microfractures, microcracks, and microcalli were observed around implants that had been placed in both low- and highdensity bone. After 18 months, the remodeling rate was still elevated.
Verna et al. [48] suggested that microcracks might act as a trigger for alveolar bone remodeling after the application of an orthodontic load.

Melsen and Lang [49] used specially designed TPS implants in monkeys that were loaded with $\mathrm{Ni}$-Ti coil springs and found that loading significantly influenced both the turnover and the density of the alveolar bone in the proximity of the implants. Yet it didn't not impede osseointegration.

When bone level was observed radiographically after orthodontic forces were retired it was noted that there were no differences compared with other researches that used the same implants but only used as fixtures for dental prosthesis.

In a research comparing the results and percentages of success that can be obtained from two-stage surgeries and one-stage surgeries when double acid-etched surface external hex titanium implants are used, Ibañez et al. [22] showed that bone level at the $12^{\text {th }}$ month was 0.58 for one-stage placed implants and 0.54 for two-stage placed implants. At the $24^{\text {th }}$ month the bone level was $0.77 \mathrm{~mm}$ and 0.68 respectively, and 0.89 and 0.83 at the $36^{\text {th }}$ month. Similar results were achieved by the same authors using Osseotite implants for immediate loading procedures [28-34].

The RFA results suggest increasing implant stability after using orthodontic forces. There was a significant difference $(\mathrm{p} \leq 0.03)$ between the initial ISQ values (mean value: 66.26$)$ and the last ones (mean value: 68.26). These results were better than those found by O'Sullivan et al. [50] when initial stability of Osseotite implants was measured in unembalmed human cadavers. Ibañez et al. [34] presented similar results on using Osseotite implants for immediate loading procedures. During this research, implant stability was measured right after surgical insertion and after some months of function. The mean ISQ value achieved after 6 to 12 month in that research was 62.3.

There were no significant difference $(p=0.4519)$ between the ISQ obtained in soft and more dense bone types when orthodontic forces were retired. These results are similar to those reported by Meredith et al. [51], which also showed that the stability of implants placed in softer bone seemed to "catch up" over time with more dense bone sites.

\section{CONCLUSIONS}

The findings of the current study prove that Osseotite implants were suitable to support the orthodontic forces applied during this investigation maintaining the osseointegration process without significant variation in bone level. Therefore, it can be concluded that Osseotite implants can be used d to support dental prosthesis once they have been used as an orthodontic anchorage.

\section{ACKNOWLEDGMENTS}

To Dr. Miriam Carranza for her contribution in the statistic analysis of this research.

\section{REFERENCES}

[1] Adell R, Lekholm U, Rockler B, Branemark PI A 15-year study of osseointegrated implants in the treatment of the edentulous jaw. Int J Oral Surg 1981; 10(6): 387-416.

[2] Lekholm U, Gunne J, Henry P, Higuchi K, Linden U, Bergstrom C, van Steenberghe D. Survival of the Branemark implant in partially 
edentulous jaws: a 10-year prospective multicenter study.Int J Oral Maxillofac Implants 1999; 14(5): 639-45.

[3] Albrektsson T, Dahl E, Enbom L, Engevall S, Engquist B, Eriksson AR, Feldmann G, Freiberg N, Glantz PO, Kjellman O, et al. Osseointegrated oral implants. A Swedish multicenter study of 8139 consecutively inserted Nobelpharma implants. J Periodontol 1988; 59(5): 287-96.

[4] Higuchi KW, Slack JM. The use of titanium fixtures for intraoral anchorage: Report of a case. Int J Oral Maxillofac Implants 1991; 6: 338-334.

[5] Block MS, Hoffman DR. A new device for absolute anchorage for orthodontics. Am J Orthod Dentofacial Orthop 1995; 107(3): 2518.

[6] Goto M, Jin-Nouchi S, Ihara K, Katsuki T. Longitudinal follow-up of osseointegrated implants in patients with resected jaws. Int J Oral Maxillofac Implants 2002; 17(2): 225-30.

[7] Roumanas ED, Freymiller EG, Chang TL, Aghaloo T, Beumer J 3rd. Implant-retained prostheses for facial defects: an up to 14-year follow-up report on the survival rates of implants at UCLA. Int $\mathbf{J}$ Prosthodont 2002; 15(4): 325-32.

[8] Thilander B, Odman J, Lekholm U. Orthodontic aspects of the use of oral implants in adolescents: a 10-year follow-up study. Eur J Orthod 2001; 23(6): 715-31.

[9] Drago CJ. Use of osseointegrated implants in adult orthodontic treatment: a clinical report. J Prosthet Dent 1999; 82(5): 504-9.

[10] Willems G, Carels CE, Naert IE, van Steenberghe D. Interdisciplinary treatment planning for orthodontic-prosthetic implant anchorage in a partially edentulous patient. Clin Oral Implants Res 1999; 10(4): 331-7.

[11] Goodacre CJ, Brown DT, Roberts WE, Jeiroudi MT. Prosthodontic considerations when using implants for orthodontic anchorage.J Prosthet Dent 1997; 77(2): 162-70.

[12] Celenza F. Implant-enhanced tooth movement: indirect absolute anchorage. Int J Periodontics Restorative Dent 2003; 23(6): 533-41.

[13] Celenza F, Hochman MN. Absolute anchorage in orthodontics: direct and indirect implant-assisted modalities.J Clin Orthod 2000; 34(7): 397-402.

[14] Higuchi KW, Snack JM. The use of titanium fixtures for intraoral anchorage: Report of a case. Int J Oral Maxillofac Implants 1991; 6: 338-334.

[15] Thilander B, Odman J, Lekholm U. Orthodontic aspects of the use of oral implants in adolescents: a 10-year follow-up study. Eur J Orthod 2001; 23(6): 715-31.

[16] Roberts WE, Engen DW, Schneider PM, Hohlt WF. Implantanchored orthodontics for partially edentulous malocclusions in children and adults.Am J Orthod Dentofacial Orthop 2004; 126(3): 302-4.

[17] Odman J, Lekholm U, Jemt T, Thilander B Osseointegrated implants as orthodontic anchorage in the treatment of partially edentulous adult patients. Eur J Orthod 1994; 16(3): 187-201.

[18] Stean H. Clinical case report: an improved technique for using dental implants as orthodontic anchorage. J Oral Implantol 1993; 19(4): 336-40.

[19] Smalley WM Implants for tooth movement: determining implant location and orientation. J Esthet Dent 1995; 7(2): 62-72.

[20] Schneider G, Simmons K, Nason R, Felton D. Occlusal rehabilitation using implants for orthodontic anchorage. J Prosthodont 1998; 7(4): 232-6.

[21] Ricci G, Aimetti M, Stablum W, Guasti A. Crestal bone resorption 5 years after implant loading: clinical and radiologic results with a 2-stage implant system. Int J Oral Maxillofac Implants 2004; 19(4): 597-602.

[22] Ibañez JC, Tahhan M, Zamar J. Performance of Double AcidEtched Surface External Hex Titanium Implants in Relation to One- and Two-Stage Surgical Procedures J Periodontol 2003; 74: 1575-1581.

[23] Friberg B, Sennerby L, Roos J, Lekholm U. Identification of bone quality in conjunction with insertion of titanium implants. A pilot study in jaw autopsy specimens. Clin Oral Implants Res 1995; 6(4): 213-9.

[24] Testori T, Wiseman L, Woolfe S, Porter SS.A prospective multicenter clinical study of the Osseotite implant: four-year interim report. Int J Oral Maxillofac Implants 2001; 16(2): 193-200.

[25] Hanggi MP, Hanggi DC, Schoolfield JD, Meyer J, Cochran DL, Hermann JS. Crestal bone changes around titanium implants. Part I: A retrospective radiographic evaluation in humans comparing two non-submerged implant designs with different machined collar lengths. J Periodontol 2005; 76(5): 791-802.

[26] Bragger U, Hugel-Pisoni C, Burgin W, Buser D, Lang NP. Correlations between radiographic, clinical and mobility parameters after loading of oral implants with fixed partial dentures. A 2-year longitudinal study. Clin Oral Implants Res 1996; 7(3): 230-9.

[27] Weber HP, Crohin CC, Fiorellini JP. A 5-year prospective clinical and radiographic study of non-submerged dental implants. Clin Oral Implants Res 2000; 11(2): 144-53.

[28] Ibanez JC, Jalbout ZN. Immediate loading of osseotite implants: two-year results. Implant Dent 2002; 11(2): 128-36.

[29] Zechner W, Trink1 N, Watzak G, Busenlechner D, Tepper G, Haas R, Watzek G. Radiologic follow-up of peri-implant bone loss around machine-surfaced and rough-surfaced interforaminal implants in the mandible functionally loaded for 3 to 7 years. Int $\mathbf{J}$ Oral Maxillofac Implants 2004; 19(2): 216-21.

[30] Loe H.The Gingival Index, the Plaque Index and the Retention Index Systems. J Periodontol 1967; 38(6): Suppl: 610-6.

[31] Sullivan D, Vincenzi G, Feldman S. Early loading of Osseotite implants 2 months after placement in the maxilla and mandible: a 5-year report. Int J Oral Maxillofac Implants 2005; 20(6): 905-12.

[32] Meredith N, Shagaldi F, Alleyne D, Sennerby L, Cawley P.The application of resonance frequency measurements to study the stability of titanium implants during healing in the rabbit tibia. Clin Oral Implants Res 1997; 8(3): 234-43.

[33] Meredith N, Book K, Friberg B, Jemt T, Sennerby L. Resonance frequency measurements of implant stability in vivo. A crosssectional and longitudinal study of resonance frequency measurements on implants in the edentulous and partially dentate maxilla Clin Oral Implants Res 1997; 8(3): 226-33.

[34] Ibanez JC, Tahhan MJ, Zamar JA, Menendez AB, Juaneda AM, Zamar NJ, Monqaut JL. Immediate occlusal loading of double acid-etched surface titanium implants in 41 consecutive full-arch cases in the mandible and maxilla: 6- to 74-month results. J Periodontol 2005; 76(11): 1972-81.

[35] Davies JE. Mechanisms of endosseous integration. [Review] [37 refs] Int J Prosthodontics 1998; 11(5): 391-401.

[36] Lazzara RJ, Testori T, Trisi P, et al. A human histologic analysis of osseotite and machined surfaces using implants with 2 opposing surfaces. Int J Periodontics Restorative Dent 1999; 19(2): 117-29.

[37] Khang W, Feldman S, Hawley CE, et al. A multi-center study comparing dual acid-etched and machined-surfaced implants in various bone qualities. J Periodontol 2001; 72(10): 1384-90.

[38] Testori T, Szmukler-Moncler S, Francetti L, et al. Immediate loading of Osseotite implants: a case report and histologic analysis after 4 months of occlusal loading. Int J Periodontics Restorative Dent 2001; 21(5): 451-9.

[39] Goene R, Bianchesi C, Huerzeler M, Del Lupo R, Testori T, Davarpanah M, Jalbout Z. Performance of short implants in partial restorations: 3-year follow-up of Osseotite implants. Implant Dent 2005; 14(3): 274-80

[40] Feldman S, Boitel N, Weng D, Kohles SS, Stach RM. Five-year survival distributions of short-length $(10 \mathrm{~mm}$ or less $)$ machinedsurfaced and Osseotite implants. Clin Implant Dent Relat Res 2004; 6(1): 16-23.

[41] Trisi P, Rebaudi A. Progressive bone adaptation of titanium implants during and after orthodontic load in humans. Int J Periodontics Restorative Dent 2002; 22(1): 31-43.

[42] Wehrbein H, Merz BR, Hammerle CH, Lang NP. Bone-to-implant contact of orthodontic implants in humans subjected to horizontal loading. Clin Oral Implants Res 1998; 9(5): 348-53.

[43] Miura F, Mogi M, Ohura Y, Hamanaka H. The super-elastic property of the Japanese NiTi alloy wire for use in orthodontics. Am J Orthod Dentofacial Orthop 1986; 90(1): 1-10.

[44] Giannelly AA, Bednar J, Dietz VS. Japanese NiTi coils used to move molars distally. Am J Orthod Dentofacial Orthop 1991; 99: 564-6.

[45] Jones RD, White JM. Rapid Class II molar correction usingan open coil jig. J Clin Orthod 1992; 26: 661-4.

[46] Aldikacti M, Acikgoz G, Turk T, Trisi P. Long-term evaluation of sandblasted and acid-etched implants used as orthodontic anchors in dogs. Am J Orthod Dentofacial Orthop 2004; 125(2): 139-47.

[47] Saito S, Sugimoto N, Morohashi T, Ozeki M, Kurabayashi H, Shimizu H, Yamasaki K, Shiba A, Yamada S, Shibasaki Y. Endosseous titanium implants as anchors for mesiodistal tooth movement 
in the beagle dog. Am J Orthod Dentofacial Orthop 2000; 118(6): 601-7.

[48] Verna C, Dalstra M, Lee TC, Cattaneo PM, Melsen B. Microcracks in the alveolar bone following orthodontic tooth movement: a morphological and morphometric study. Eur J Orthod 2004; 26(5): 459-67.

[49] Melsen B, Lang NP, Biological reactions of alveolar bone to orthodontic loading of oral implants. Clin Oral Implants Res 2001; 12(2): $144-52$
[50]

O'Sullivan D, Sennerby L, Meredith N. Measurements comparing the initial stability of five designs of dental implants: a human cadaver study. Clin Implant Dent Relat Res 2000; 2(2): 85-92.

[51] Friberg B, Sennerby L, Meredith N, Lekholm U. A comparison between cutting torque and resonance frequency measurements of maxillary implants. A 20-month clinical study. Int J Oral Maxillofac Surg 1999; 28(4): 297-303

Received: November 21, 2007

Accepted: February 13, 2008

(C) Marta and Carlos; Licensee Bentham Open.

This is an open access article licensed under the terms of the Creative Commons Attribution Non-Commercial License (http://creativecommons.org/licenses/ by-nc/3.0/) which permits unrestricted, non-commercial use, distribution and reproduction in any medium, provided the work is properly cited. 